\title{
Activation of Cyclin-Dependent Kinase 5 Is a Consequence of Cell Death
}

\author{
Yixia Ye, ${ }^{1}$ Antonella Tinari, ${ }^{2}$ Walter Malorni, ${ }^{3}$ Richard A. Lockshin, ${ }^{4}$ and Zahra Zakeri ${ }^{1}$ \\ ${ }^{1}$ Department of Biology, Queens College and Graduate Center of the City University of New York, Flushing, NY 11367, USA \\ ${ }^{2}$ Department of Technology and Health, Higher Institute for Health, 00161 Rome, Italy \\ ${ }^{3}$ Department of Drug Research and Evaluation, Highest Institute for Health, 00161 Rome, Italy \\ ${ }^{4}$ Department of Biological Sciences, St. John's University, Jamaica, NY 11439, USA \\ Correspondence should be addressed to Zahra Zakeri, zahra_zakeri@hotmail.com
}

Received 28 April 2009; Revised 20 June 2009; Accepted 14 July 2009

Recommended by Mauro Piacentini

Cyclin-dependent kinase 5 (Cdk5) is similar to other Cdks but is activated during cell differentiation and cell death rather than cell division. Since activation of Cdk5 has been reported in many situations leading to cell death, we attempted to determine if it was required for any form of cell death. We found that Cdk5 is activated during apoptotic deaths and that the activation can be detected even when the cells continue to secondary necrosis. This activation can occur in the absence of Bim, calpain, or neutral cathepsins. The kinase is typically activated by p25, derived from p35 by calpain-mediated cleavage, but inhibition of calpain does not affect cell death or the activation of Cdk5. Likewise, RNAi-forced suppression of the synthesis of Cdk5 does not affect the incidence or kinetics of cell death. We conclude that Cdk5 is activated as a consequence of metabolic changes that are common to many forms of cell death. Thus its activation suggests processes during cell death that will be interesting or important to understand, but activation of Cdk5 is not necessary for cells to die.

Copyright (C) 2009 Yixia Ye et al. This is an open access article distributed under the Creative Commons Attribution License, which permits unrestricted use, distribution, and reproduction in any medium, provided the original work is properly cited.

\section{Introduction}

Cyclin dependent kinase 5 (Cdk5) is a unique member of the family of cyclin-dependent kinases, as its activity does not correlate with cell cycle progression [1]. It is activated in many instances of neuronal and other cell differentiation and, curiously, quite often in cell death. Thus activated Cdk5 is presumed to function in cell death. We therefore decided to explore the importance of Cdk5 to cell death.

Cdk5, homologous to the prototypic Cdk, human Cdc2, is also known as neuronal Cdc-2-like kinase (Nclk) $[2,3]$. Cdk5 activity is required for neurite migration [4], axon patterning [5], cortical lamination [6], neuronal secretion [7], neuronal adhesion [8], differentiation of oligodendrocytes [9], formation of synaptic structure and plasticity, the maintenance of neuronal cytoarchitecture [10], and perhaps other functions in the brain. Cdk5 kinase is active in many other cell types, where it may be involved in differentiation [9], exocytosis [11], gene expression [12], cell migration [13], tissue regeneration, and wound healing and cell death $[14,15]$.
Cdk5 is activated in neuronal cell death, such as cell death induced by removal of NGF in differentiated PC12 cells [16], cell death in the dorsal root ganglia and the trigeminal ganglia [17], and neuronal cell death in neurological diseases $[3,18]$. Active Cdk5 kinase is also seen in nonneuronal cell death [19-22]. Cdk5 protein and kinase activity are elevated in embryonic tissues during normal developmental cell death in almost all organs manifesting cell death as well as when death is induced by cyclophosphamide (CP) or retinoic acid $[20,23,24]$. This activation has been seen in several cell lines during cell death induced by various toxins $[25,26]$. Cdk5 kinase is likewise activated in several diseases, such as Alzheimer's, Huntington's, Parkinson's diseases, Amyotrophic Lateral Sclerosis, and stroke [3, 18, 27, 28]. The consistent activation of Cdk5 in all types of cell death suggests a fundamental role for this enzyme in activation or progression of cell death. However there is no direct demonstration of a function for Cdk5 in cell death. Here we present evidence that Cdk5 is dispensable for cell death, and that its activation appears to be a response to, rather than a controlling mechanism of, cell death. 
We previously showed that Cdk5 may be activated in the absence of caspase-3, caspase-9, Apaf-1, or p53 [25]. Here we further demonstrate that Cdk5 activation is independent of Bim (a Bcl-2 family member in mitochondria), and cathepsins, such as cathepsin B, D, or L (the most abundant lysosomal proteases) during cell death.

As with other Cdks, monomeric Cdk5 is enzymatically inactive; it is activated by association with its specific activators. In differentiating neurons, p35 and p39 are two major activators $[29,30]$. However, other activators such as cyclin E [31] and RINGO [32] can also regulate Cdk5 activity. TNF $\alpha$ can modulate Cdk5 directly without affecting its activator [33]. More commonly, Cdk5 is activated by p25, which is generated by the calpain-mediated cleavage of $\mathrm{p} 35$ to p25 [25-27]. Although this interpretation is consistently reported, here we demonstrate that Cdk5 can be activated in the absence of p25 or p29 (the calpain cleavage products of p35 and p39) and that cell death is not affected by the inhibition of calpain. We conclude that Cdk5 may be activated by means other than interaction with p 25 and p29. Finally, since downregulation of Cdk 5 expression and activity does not materially affect cell death, its activity appears to be a product, rather than a cause, of cell death.

\section{Materials and Methods}

2.1. Antibodies and Reagents. The calpain inhibitor, PD150606 (Cat\# 513022), were obtained from CalBiochem (La Jolla, CA). Cyclophosphamide (CP Cat\#C0768) and Camptothecin (CPT Cat\# C9911) was obtained from Sigma (St. Louis, MO). The rabbit polyclonal IgG antibodies used include anti-Cdk5 (C-8, Cat\# sc-173) from Santa Cruz Biotechnology (Santa Cruz, CA), anti-p35 (C-19, Cat\# P9489), and anti-LC3-II (Cat\# L7543) antibodies from Sigma (St. Louis, MO), and anti-phosphohistone H1 (Cat\# 06-597) antibody from Upstate Biotechnology (Lake Placid, NY). The mouse monoclonal antibody used is antiactive caspase-3 antibody (Cat\# 559565) from BD PharMingen (San Diego, CA).

2.2. Cell Culture and Treatment. (1) C8 cells: C8 is a mouse embryonic fibroblast (MEF) cell line transformed with E1A and ras (gift from Dr. Scott Lowe, Cold Spring Harbor Laboratory). Cells were maintained in DMEM (Dulbecco's Modified Eagle Medium, Life Technologies, Rockville, MD) supplemented with $10 \%$ fetal bovine serum, $50 \mathrm{U} / \mathrm{mL}$ penicillin and $100 \mu \mathrm{g} / \mathrm{mL}$ streptomycin, at $37^{\circ} \mathrm{C}$ in a humidified atmosphere of $7.5 \% \mathrm{CO}_{2}$. At $80 \%$ confluence, cells were exposed in DMEM containing $1 \%$ FBS to $50 \mu \mathrm{M}$ camptothecin (CPT, dissolved in DMSO) or other cytotoxins, for 8 hours or 18 hours, times determined to represent modest and high levels of cell death. To block calpain activation induced by CPT, $15 \mu \mathrm{M}$ of the synthetic calpain inhibitor PD150606 was coadministered with CPT, and cells were incubated for 8 hours or 18 hours.

(2) COS-7 cells. COS-7 cells were obtained from the American Type Culture Collection (ATCC) and cultured as above. At $80 \%$ confluence, cells were exposed in DMEM containing $1 \%$ FBS to siRNA of Cdk5 to block Cdk5 expression and CPT $50 \mu \mathrm{M}$ was co-administered for 48 hours to induce cell death.

(3) Cathepsin-B -/- , -D -/- , -L -/- and Wild Type mouse embryo fibroblast cells. Mouse embryo fibroblast (MEF) cells obtained from transgenic mouse embryos with single knockout genotypes of cathepsin-B, -D, or $-\mathrm{L}$ or wild type (WT) were immortalized with SV40 (Gift from Dr. Marianne Boes, Harvard Medical School). Cells were cultured in DMEM (Dulbecco's Modified Eagle Medium, Gibco BRL Life Technologies, cat\# 12800-017) as above. At $80 \%$ confluence, cells were treated in DMEM containing $1 \%$ FBS with different cytotoxic reagents, such as $50 \mu \mathrm{M}$ camptothecin (CPT, dissolved in DMSO), and cells were collected at 8,24 , and 72 hours.

\subsection{Injection of CP into Pregnant Mice and Collection of} Embryos. Bim heterozygous mice (gift from Dr. Phillippe Bouillet, the Walter and Eliza Hall Institute of Medical Research) were mated overnight, and pregnant female mice were injected intraperitoneally with $10 \mathrm{mg} / \mathrm{kg}$ body weight of CP dissolved in $0.9 \%$ saline at gestation day 12.5 . The embryos were removed 18 hours after exposure to CP, and sections were prepared as described below [20].

2.4. Tissue, Slide Preparation, and Microscopy. Pregnant female mice that had been injected with CP at gestation day 12.5 were sacrificed by cervical dislocation one day later, and the embryos were removed. Embryos were washed with $1 \mathrm{X}$ PBS (Phosphate-Buffered Saline, $137 \mathrm{mM} \mathrm{NaCl}, 2.68 \mathrm{mM}$ $\mathrm{KCl}, 4.3 \mathrm{mM} \mathrm{Na} \mathrm{HPO}_{4}, 1.4 \mathrm{mM} \mathrm{KH} \mathrm{PO}_{4}, \mathrm{pH} 7.4$ ), and the tail was taken for genotyping. Embryos were washed with PBS, fixed in 4\% paraformaldehyde with shaking at $4{ }^{\circ} \mathrm{C}$ for 18-24 hours, and partially dehydrated in $20 \%$ sucrose solution in PBS for 2 days. Embryos were then embedded in OCT compound (Miles, Elkhart, IN) and frozen in isopropanol/liquid $\mathrm{N}_{2}$. Special care was used in the orientation of the mouse embryo or limb samples during the embedding procedure to make sure the cutting section represented a good map of the tissue. Frozen sections $(5 \mu \mathrm{m})$ were cut at $-20^{\circ} \mathrm{C}$ and placed on VECTABOND-coated slides and stored at $-80^{\circ} \mathrm{C}$ prior to use.

2.5. Immunohistochemistry. In situ proteins were detected using the ABC (Avidin-Biotinylated-peroxidase Complex) kit (Vectastain ABC kit, Vector Laboratory, Burlingame, CA). Sections were quenched with $0.3 \%$ hydrogen peroxide in methanol at RT for 20 minutes to abolish endogenous peroxidase activity. After three washes with PBST $(0.1 \%$ Tween 20 in PBS), sections were incubated in blocking solution at RT for 1 hour and treated with primary antibody (antibodies against Cdk5 and p35: $0.2 \mu \mathrm{g} / \mathrm{mL}$; active caspase 3: $0.5 \mu \mathrm{g} / \mathrm{mL}$ ) at $4^{\circ} \mathrm{C}$ in a humidified chamber overnight. Following three washes with PBST, secondary biotinylated antibody was applied to the sections for 1 hour at RT. Sections were then washed with PBST $3 \mathrm{x}$ and incubated with $\mathrm{ABC}$ reagent for 2 hours at RT. Sections were washed with 
PBST 3x before being visualized with DAB, counterstained with methylene blue, and mounted with Permount.

2.6. Western Blot. Cells or tissues were lysed in RIPA buffer (50 mM Tris, $\mathrm{pH} 7.5,150 \mathrm{mM} \mathrm{NaCl}, 1 \%$ Triton 100X, $0.1 \%$ SDS, $0.5 \%$ sodium deoxycholate, $2 \mathrm{mM}$ EDTA, and protease inhibitor cocktail tablets (Boehringer Mannheim, Germany)), and cell/tissue debris was removed by centrifugation at $13000 \mathrm{rpm}$ for 30 minutes at $4^{\circ} \mathrm{C}$. Protein concentration was determined using the Bio-Rad microassay (Bio-Rad laboratories, Hercules, CA). Equal amounts of protein were run on $8 \%, 12.5 \%$ or $15 \%$ SDS-polyacrylamide gels after addition of an equal volume of $2 \mathrm{X}$ Laemmli loading buffer (100 mM Tris, pH 7.5, 4\% SDS, 20\% glycerol, 0.002\% bromophenol blue) [34]. After protein transfer, nitrocellulose membrane blots were blocked with $5 \%$ nonfat dry milk in PBST for 30 minutes and incubated with different primary antibodies on the shaker overnight at $4^{\circ} \mathrm{C}$. After three washes with PBST, blots were incubated with horseradish peroxidase (HRP) conjugated goat antirabbit antibody (Jackson Immuno Research Laboratory, West Grove, PA) for 1 hour at RT followed by 3 washes. The immune complexes were detected by chemiluminescence (ECL Plus kit, Amersham, Chicago, IL) and exposed to autoradiographic film.

2.7. In Vitro Histone H1 Kinase Assays. Equal amounts of lysates from different cell samples were incubated with $1.5 \mu \mathrm{g} / \mathrm{mL}$ Cdk5 antibody for 1 hour at $4^{\circ} \mathrm{C}$, and then purified by the addition of protein A-Sepharose (Boehringer Mannheim, Germany). The precipitated beads were equilibrated in kinase buffer $(50 \mathrm{mM}$ Tris, pH7.5, $10 \mathrm{mM}$ $\mathrm{MgCl}_{2}, 1 \mathrm{mM}$ DTT, $20 \mathrm{mM}$ EGTA, $0.1 \mathrm{mM}$ sodium vanadate, $80 \mathrm{mM} \beta$-glycerophosphate) and collected by centrifugation. Histone H1 kinase assays were performed in kinase buffer supplemented with $200 \mathrm{mM}$ ATP, $50 \mu \mathrm{g} / \mathrm{mL}$ calf thymus histone H1 (Boehringer Mannheim, Germany), and $5 \mu \mathrm{M}$ cAMP-dependent protein kinase inhibitor (Sigma, St. Louis, $\mathrm{MO}$ ) at $30^{\circ} \mathrm{C}$ for 30 minutes. An equal volume of $2 \mathrm{X}$ Laemmli buffer was added to each sample before they were denatured at $100^{\circ} \mathrm{C}$ for 2 minutes. The phosphorylated histone $\mathrm{H} 1$ was detected by western blot described as above, using anti-phosphohistone $\mathrm{H} 1$ primary antibody.

2.8. Detection of Cell Death by Trypan Blue. The loss of membrane integrity exhibited in dead and dying cells allows the preferential uptake of vital dye trypan blue. At the end of the treatment, cells were pelleted and washed with PBS. $100 \mu \mathrm{L}$ of well-suspended cells was mixed with $100 \mu \mathrm{L}$ of $0.4 \%$ trypan blue solution (in PBS) and left at room temperature (RT) for 5 minutes. Cells were then viewed under a light microscope and blue stained cells were judged non-viable.

2.9. Measurement of Nuclear Condensation by Bis-Benzimide. The DNA fluorochrome bis-benzimide (Hoechst 33258, Sigma, St. Louis, MO) was used to stain fragmented nuclei of apoptotic cells. Briefly, cells were trypsinized, pelleted and washed once with ice cold PBS. The cells were then resuspended and fixed in 3\% paraformaldehyde solution (in PBS) for 30 minutes, washed with ice cold PBS, and incubated with $16 \mu \mathrm{g} / \mathrm{mL}$ bis-benzimide in PBS for 25 minutes at RT. Finally, the cells were washed with ice cold PBS once and resuspended in PBS. $20 \mu \mathrm{L}$ of the cell suspension was evenly distributed on a slide and covered with a coverslip to be viewed using an Eclipse TE300 microscope (Nikon Inc., Melville, NY).

2.10. RNA Interference. The target sequences were designed by the siRNA target finder in http://www.ambion.com/ techlib/misc/siRNA_finder.html. Five 21nt target sequences were selected randomly. siRNAs were prepared by using Silence siRNA Construction Kit (Ambion Cat\# 1620). The concentration of siRNA was determined by reading absorbance at $260 \mathrm{~nm}$. siRNAs were transfected into mammalian cells, such as COS-7 cells by using siPORT Amine transfection Agent (Ambion Cat\# 4502). Western blotting as described was used to assay the efficiency.

2.11. Electron Microscopy. Cells treated with different death inducers were prefixed in $2.5 \%$ glutaraldehyde in $0.2 \mathrm{M}$ cacodylate buffer, $\mathrm{pH} 7.2$, for 30 minutes, and then washed in cacodylate buffer twice. Cells were gently scraped off with a rubber policeman and centrifuged in Eppendorf tubes at $1200 \mathrm{~g}$ for 5 minutes. The postfixation was with $1 \%$ osmium tetroxide for 2 hours at room temperature, after which the cells were washed with cacodylate buffer $3 \mathrm{x}$ and dehydrated through ascending ethanol concentrations $(50 \%-100 \%)$ twice each for 5 minutes. The samples were sent to Dr. Walter Malorni at Higher Institute for Health, Italy, for further processing. Samples were embedded in Epon 812, and thin sections were cut, after which the sections were stained with uranyl acetate and sodium citrate and observed with Zeiss EM10 electron microscope at 8000X magnification.

\section{Results}

3.1. Cdk5 Activation Is Independent of Bim and Cathepsins. Sun et al. showed that inhibition of Cdk5 activity can rescue mitochondrial damage following administration of neuronal toxins [35], suggesting a role for C $\mathrm{Ck} 5$ in the mitochondrial pathway of apoptosis. To examine this possibility we looked at the role of Bim in activating Cdk5. Bim, a member of the BH3-only pro-apoptotic Bcl-2 family, induces the release of cytochrome $\mathrm{c}$ from mitochondria during cell death through binding with Bax and Bak (the members of pro-apoptotic Bcl-2 family) to induce their oligomerization and activation; alternatively, they engage the antiapoptotic proteins to prevent them from countering Bax and Bak activation. To examine the effect of Bim on Cdk5 activation, we used bim transgenic mouse embryos that were exposed to cyclophosphamide (CP), which can induce massive cell death during development [20]. Thus these knockouts can help us to understand the relationship between Cdk5 and mitochondria during cell death. First, we used antiCdk5 antibody and immunohistochemistry to examine Cdk5 
activity in bim $+/+$ and bim -/- mouse embryos after exposing the mothers to $\mathrm{CP}$ as is described in Materials and Methods. The antibody detects active kinase $[17,24]$.

We found Cdk5-positive cells in bim $+/+$ untreated control and CP-treated embryos and also in bim -/ - untreated control and CP-treated mouse embryos (Figure 1(a)(A)). The amount of Cdk5 activation was analyzed by $t$-test by comparing the number of cells showing Cdk5 activation from 3 to 5 fields in different sections at high magnification (400X ). Cdk5 activity is significantly increased in both CPtreated bim $+/+$ mouse embryos and CP-treated bim -/mouse embryos (Figure 1(a)(B)), indicating that $\mathrm{CP}$ can induce Cdk5 activation during cell death whether or not Bim is activated. Cdk5 activation appears to be independent of Bim. Furthermore, we performed TUNEL to examine cell death induced by CP in both bim -/- and caspase- $3-/-$ mouse embryos and found that CP-induced cell death is not at all dependent on Bim, in contrast to the case for caspase3 , where we find a downregulation of CP-induced cell death (data not shown).

An alternative common pathway to death involves substantial autophagy. We therefore examined the interaction of lysosomes and Cdk5 activity during cell death. For these experiments we used mouse embryonic fibroblast cells from transgenic mouse embryos with single knockouts of cathepsin $\mathrm{B}, \mathrm{D}$, or $\mathrm{L}$ to determine whether or not these cathepsins controlled Cdk5 activity. All cells were treated for 24 hours or 72 hours with camptothecin (CPT), which inhibits DNA topoisomerase I and thus DNA replication [36]. First, the amount of cell death was determined by trypan blue exclusion. (We also performed TUNEL, Hoechst staining and EM. These data, which were consistent, will be presented in another paper since this paper is focused on the relationship of Cdk5 activity and cell death rather than the mode of death.) These cells were somewhat sensitive to low serum (1\% FBS), so that untreated control WT or cathepsin B, D, or $\mathrm{L}-/-$ cells suffered $4 \%-8 \%$ death by 24 hours and $5 \%-12 \%$ after 72 hours. In WT cells, after 24 hours exposure, CPT induced $27 \%$ death by 24 hours and $99 \%$ by 72 hours; the corresponding numbers for cathepsin $\mathrm{B}, \mathrm{D}$, and $\mathrm{L}-/-$ cells were $7 \%, 11 \%$, and $8 \%$ cell death induced by CPT at 24 hours and 41,39 , and $47 \%$ at 72 hours (Figure 1(b)(A)). The absence of at least one cathepsin modestly protects cells or at least delays their death, but cathepsins $\mathrm{B}, \mathrm{D}$, and $\mathrm{L}$ are not necessary for cell death induced by CPT.

We had previously determined that Cdk5 is a stable protein and that the level of Cdk5 protein does not change during induced cell death $[20,23,25]$. Here as well we found similar levels of Cdk5 expression in both untreated control and CPT treated cells in both wild type and cathepsin null cells (Figure 1(b)(B)). The expression of Cdk5 protein was not affected by either cell death or lack of cathepsins. We therefore evaluated activation of Cdk5 by the production of p25 and kinase assay.

First we determined cleavage of the $35 \mathrm{kDa}$ protein to $25 \mathrm{kDa}$. Wild type and cathepsin $\mathrm{B}, \mathrm{D}$, or $\mathrm{L}-/-$ cells were exposed to CPT for 72 hours, at which time massive cell death was induced. Equal amounts of protein were extracted as in Materials and Methods, separated on a $12.5 \%$ SDS-
PAGE gel, and subjected to western blot. CPT caused the generation of a band at $25 \mathrm{kDa}$ (Figure $1(\mathrm{~b})(\mathrm{C})$ ). Thus lack of cathepsin B, D, or L did not affect the generation of p25 during cell death. Next we examined the activity of Cdk5 by its ability to phosphorylate histone H1. Cdk5 kinase was activated in CPT-treated wild type cells and CPT-treated cathepsin B, D, or L - / - cells after 72 hours exposure of CPT, as determined by detection of the band of phosphorylated histone $\mathrm{H} 1$ at $31 \mathrm{kDa}$ (Figure $1(\mathrm{~b})(\mathrm{D})$ ). By these several criteria, activation of Cdk5 kinase is not affected by the absence of any of these cathepsins. We conclude that Bim and cathepsin B, D, or $\mathrm{L}$ are not required to activate Cdk5 during cell death. The forms of cell death vary according to the knockouts and cannot readily be assigned to the classical triumvirate of "apoptosis, autophagy, necrosis." We will discuss this issue elsewhere in more expanded form and address here as aggregate cell death measured by trypan blue.

Since activation of Cdk5 did not depend on any of these factors, we asked the inverse question, whether Cdk5 activation influenced the sensitivity of cells to death or the type of death that they underwent. We therefore examined the impact of downregulation of Cdk5 activity on cell death.

\subsection{Blocking Generation of P25 Does Not Protect Cells from} Death or Prevent Activation of Cdk5 during Cell Death. As mentioned above Cdk5 is activated by the truncated protein p25 during cell death. Here we asked if preventing generation of p25 would affect Cdk5 activity and cell death. We exposed C8 cells, which are primary mouse embryonic fibroblast cells transformed with E1A and ras, to camptothecin (CPT) and measured cell death by trypan blue dye exclusion. To assess the involvement of p25 in the activation of Cdk5 and the induction of cell death, we used the calpain inhibitor PD150606. This calpain inhibitor inhibits generation of p25 in C8 cells [25]. We confirmed, using western blot and antibodies detecting both p 35 and p25, that p 25 formation was blocked [25]. As shown in Figure 2(a), the untreated control and PD-treated cells alone showed 7.6\% and 7.7\% background cell death respectively after 8 , and $15.0 \%$ and $15.7 \%$ after 18 hours. Although C8 cells are somewhat sensitive to low serum concentration (1\% FBS during treatment), PD is not toxic. $50 \mu \mathrm{M}$ CPT killed $43.0 \%$ of C8 cells within 8 hours and $90.2 \%$ by 18 hours (Figure 2(a)). Addition of $15 \mu \mathrm{M}$ calpain inhibitor PD simultaneously with CPT did not alter these figures; $44.4 \%$ of cells were dead by 8 hours and $90.6 \%$ by 18 hours (Figure 2(a)). We also looked for nuclear condensation and nuclear fragmentation by Hoechst staining. Nuclear fragmentation was seen in cells treated with CPT for 18 hours in the presence or absence of $\mathrm{PD}$ and the number of fragmented nuclei correlated with the number of dead cells detected by trypan blue exclusion (data not shown). Thus, preventing the production of $\mathrm{p} 25$ does not affect the toxicity of CPT or the type of cell killing.

We then asked whether inhibiting generation of p25 affected the expression and activation of Cdk5. Cell lysates were run on $12 \%$ SDS-PAGE and analyzed by western blot using anti-Cdk5 antibody, as shown in Figure 2(b)(A). A similar amount of Cdk5 protein is found in both untreated 

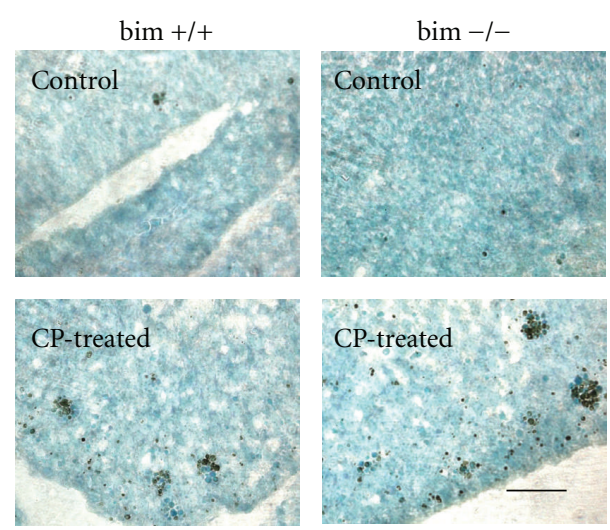

(A)

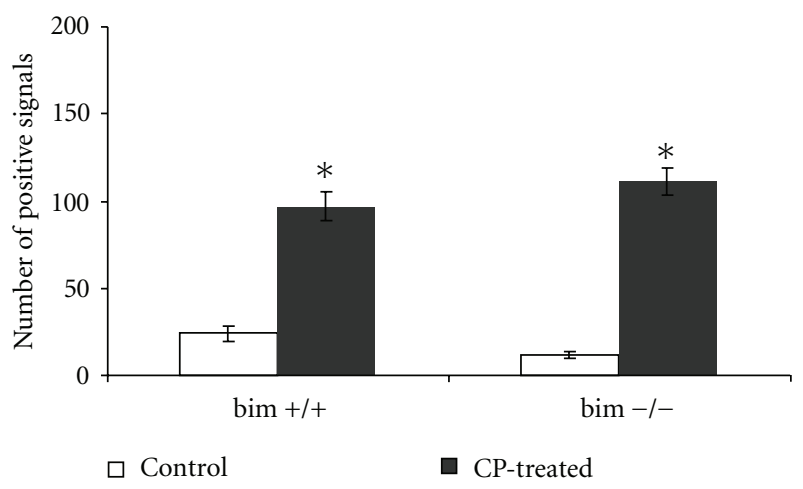

(B)

(a)

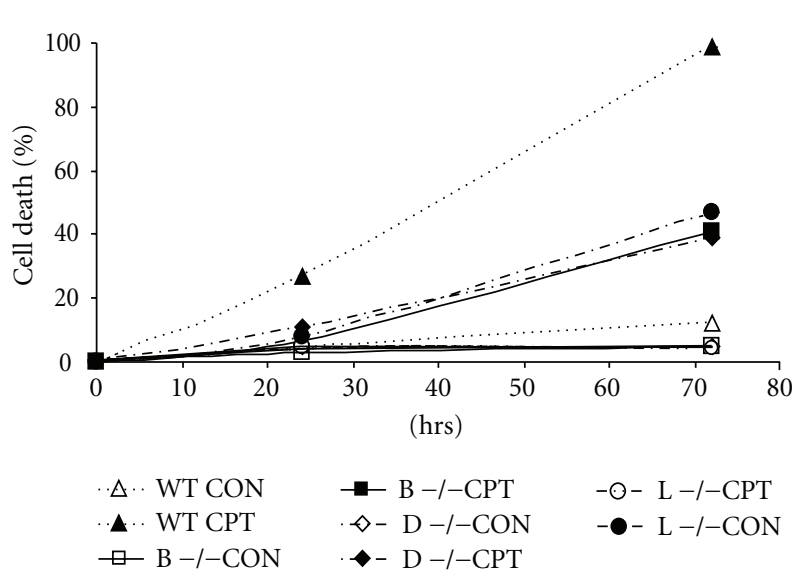

(A)

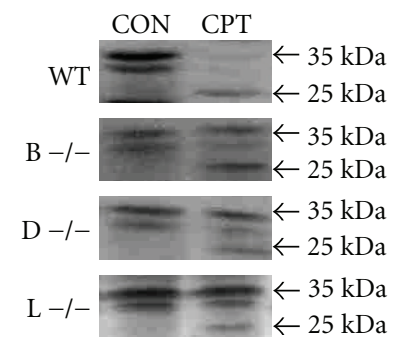

(C)

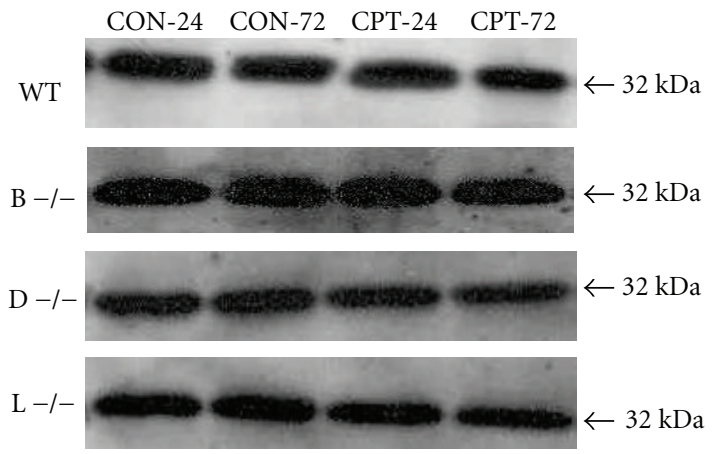

(B)

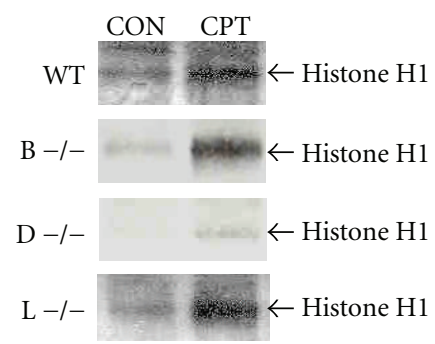

(D)

(b)

FIGURE 1: Cdk5 activation is independent of Bim and cathepsins. (a) Pregnant female mice were injected intraperitoneally as described in Section 2 . Cdk 5 activation by immunohistochemistry showed many cells with Cdk 5 activation labeled by Cdk 5 antibody in bim $+/+$ and bim -/- mouse embryos with or without CP treatment, 400X. (A) Positive signals were counted in 3-5 fields of 400X, and the number of positive signals per field was used for plot and analyzed by t-test. (B) The error bars represent the standard deviation from at least three individual experiments $\left({ }^{*} P<.05\right)$. (b) Wild type and cathepsin $\mathrm{B}, \mathrm{D}$, and $\mathrm{L}-/-$ cells were incubated with $\mathrm{CPT}(50 \mu \mathrm{M})$. (A) At 24 and 72 hours, the amount of cell death was determined by trypan blue exclusion. The error bars represent standard deviation obtained from at least 3 independent experiments. Protein samples were isolated from cells with RIPA buffer. (B) Western blot analysis of equal amounts of cell lysates from cells using Cdk5 antibody showed an unchanged level of Cdk5 protein $(32 \mathrm{kDa})$ during cell death. (C): Equal amounts of cell lysates from wild type and cathepsin B, D, and L - / - cells incubated with CPT $(50 \mu \mathrm{M})$ for 72 hours were used for western blot using p35 antibody. These cells demonstrated an induction of p25 during CPT-induced cell death in the absence of the cathepsins. (D) Histone H1 kinase activity induced during cell death was detected in Cdk5 immunoprecipitates in wild type cells: cathepsin B -/- cells, cathepsin D -/- cells, and cathepsin L -/- cells following 72 hours treatment with CPT. The histone H1 phosphorylated by Cdk5, as detected by western blot, increased corresponding to cell death in controls and knockouts. Cdk5 is a relatively stable protein in cells and the expression of Cdk 5 by western can be used as a loading control [20,25]. Scale mark equals $100 \mu \mathrm{M}$. 

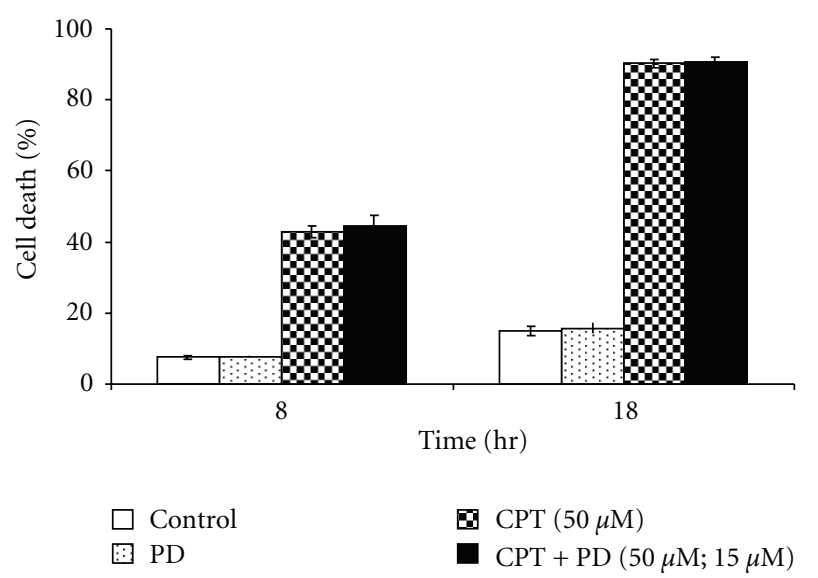

(a)

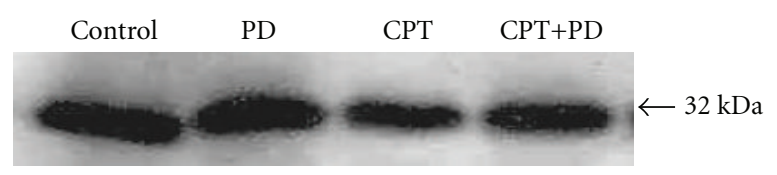

(A)

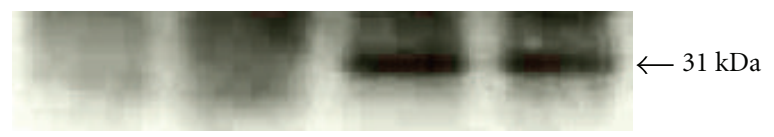

(B)

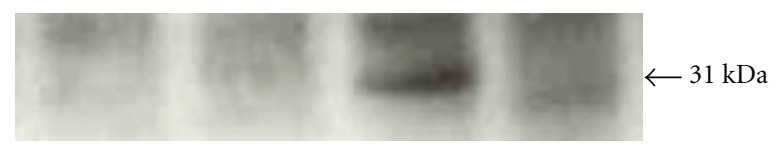

(C)

(b)

Figure 2: Inhibition of calpain does not protect fibroblast C8 cells from CPT-induced cell death or activation of Cdk5. (a) C8 cells were exposed to $50 \mu \mathrm{M}$ CPT in the presence or absence of $15 \mu \mathrm{M}$ calpain inhibitor, PD, for 8 hours or 18 hours. The amount of cell death was measured by trypan blue exclusion. The error bars represent the standard deviation from at least three individual experiments. CPT killed $\sim 40 \%$ of the cells within 8 hours and $\sim 90 \%$ by 18 hours, but PD did not affect the toxicity. (b) Cells treated with $50 \mu \mathrm{M}$ $\mathrm{CPT}$ or CPT plus $15 \mu \mathrm{M}$ PD were collected and lysed by RIPA buffer. (A) Western blot of Cdk5 in equal amounts of cell lysates from cells treated with CPT or CPT + PD for 18 hours showed an unchanged level of Cdk5 protein $(32 \mathrm{kDa})$ during cell death. ((B) and (C)) Histone $\mathrm{H} 1$ kinase activity of $\mathrm{Cdk} 5$ immunoprecipitates was measured using histone $\mathrm{H} 1$ as substrate. The histone $\mathrm{H} 1$ phosphorylated by Cdk5 was detected by western blot $(31 \mathrm{kDa})$. The kinase activity reflected the amount of cell death induced, following 8-hour (B) or 18-hour (C) treatment with CPT in the presence or absence of PD. PD did not affect the amount of histone kinase activity seen at 8 hours, though by 18 hours more was lost in the presence of $\mathrm{PD}$ than in its absence.

control and treated cells in the presence or absence of PD. Cdk5 activity was not detected in untreated or PD-treated control C8 cells at either 8 or 18 hours. In contrast, after 8 hours of exposure to CPT, Cdk5 kinase was activated in CPT-treated cells even when the generation of p25 was blocked by calpain inhibitor PD (Figure 2(b)(B)). After 18 hours, Cdk5 remained activated in cells exposed to CPT alone but was no longer detected as activated in cells exposed to both CPT and PD (Figure 2(b) (C)). The loss of activated Cdk5 may result from the fact that by 18 hours most of the cells have died and they are at the last stages of necrosis as shown below.

These data suggest that the amount of cell death and level of Cdk5 activation are not affected by inhibiting the generation of p25, and therefore molecules other than p25 may activate Cdk5 during cell death.

3.3. The Type of Cell Death Is Not Altered by Inhibiting the Production of P25. We also considered the possibility that Cdk5 influences the manner or type of cell death. Since caspase- 3 activation is a hallmark for apoptotic cell death, we measured caspase- 3 activation by western blot using antiactive caspase- 3 antibody. Caspase- 3 was activated to a similar extent in C8 cells exposed to CPT for 8 hours and 18 hours whether or not calpain inhibitor was present (Figure 3(a)(A)). These cells are also capable of fragmenting their nuclei (data not shown). We examined morphological changes during induced cell death both with and without generation of $\mathrm{p} 25$. As compared to the untreated normal control cells and PD-treated cells (Figures 3(b)(A) and $3(\mathrm{~b})(\mathrm{B}))$, CPT-treated cells in both the presence and absence of PD at 8 hours treatment (Figures 3(b)(C) and 3(b)(D)) displayed condensed and marginated chromatin indicative of apoptosis. The cytoplasm was vacuolated (potentially dilated ER cisternae) in some of the cells, indicative of cells with substantial osmotic problems. At 18 hours the CPT-treated cells in the presence or absence of PD were undergoing secondary necrosis, as indicated by the disintegration of the outer plasma membrane and organelles and diffuse appearance of the chromatin which nevertheless can still be identified as deriving from apoptosis (Figures 3(b)(E) and $3(\mathrm{~b})(\mathrm{F}))$, indicating the advanced stage of CPT-induced cell death.

Since we found some vacuolization (Figures 3(b)(C) and 3(b)(D), and data not shown) in the dying cells although they did not have a typical morphology of autophagosomes, we examined the activity of one marker of autophagy-that of cleavage of LC3-I to LC3-II in our cells after 8 hours and 18 hours of treatment. $\beta$-tubulin was used a loading control (Figure $3(\mathrm{a})(\mathrm{C})$ ). We found no difference in the level of generation of LC3-II in any of the cells examined (Figure 3(a)(B)).

3.4. Cells Are Not Protected from Death by Downregulation of Cdk5. p25 is considered to be the most important but not exclusive activator of Cdk5. Since cell death is not affected by the lack of p25, we asked how cell death would be impacted if Cdk5 were downregulated by RNAi. We introduced into cells five different dsRNAs designed by Ambion (described in Materials and Methods). In COS-7 cells, some dsRNAs can decrease the expression of $\mathrm{Cdk} 5$ as determined by western blot (Figure 4(a)). One of the dsRNAs (Cdk5-1, Figure 4(a)) lowered the expression of Cdk5 proteins by $84 \%$. The dsRNA of Cdk5-3 inhibited Cdk5 expression $60 \%$ but Cdk52 dsRNA did not block expression of Cdk5 (Figure 4(a)). 


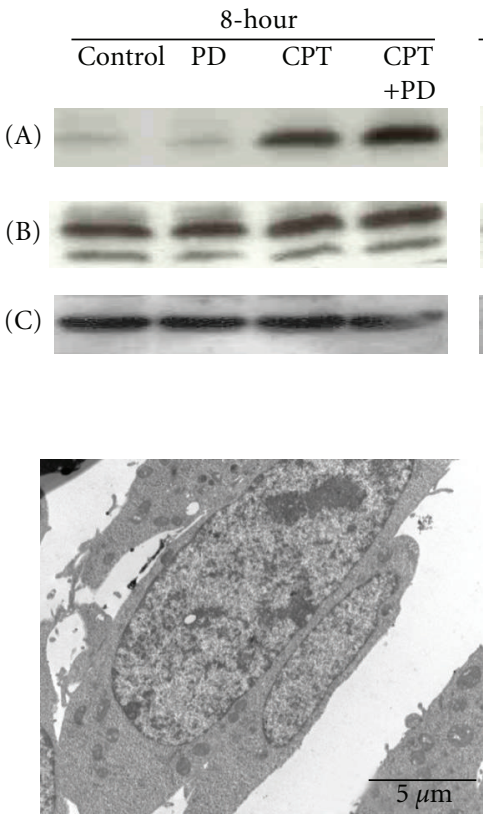

(A)

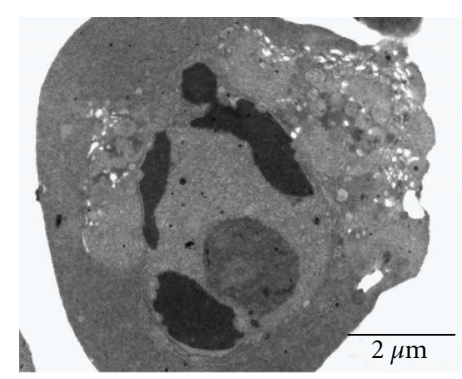

(C)

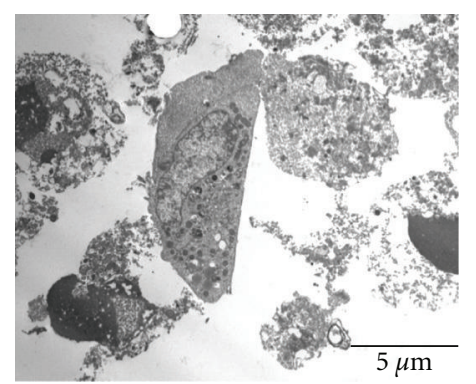

(E)

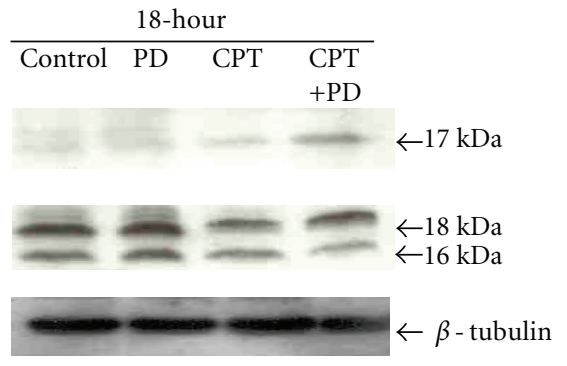

(a)

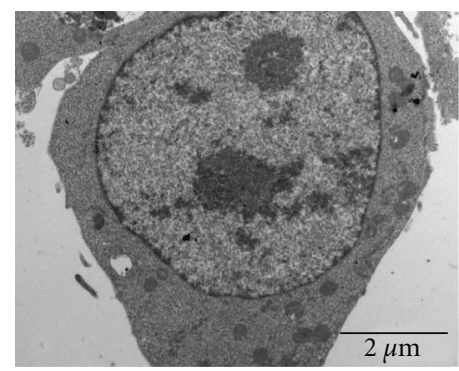

(B)

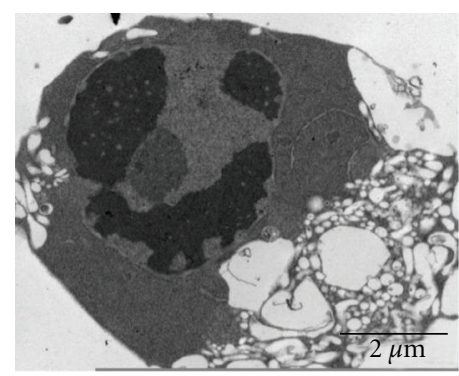

(D)

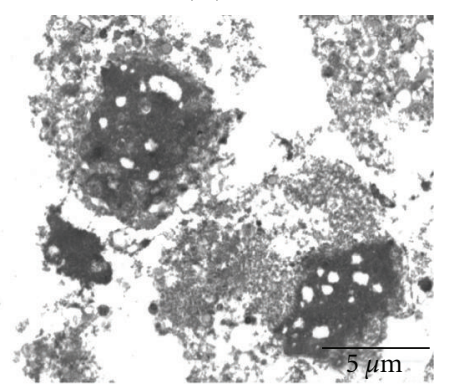

(F)

(b)

FIGURE 3: Inhibiting production of p25 does not alter the mode of cell death induced by CPT. (a) Western blot of equal amounts of protein samples from C8 cells treated with CPT or CPT + PD. (A) Cells exposed for 8 hours or 18 hours showed the activation of caspase-3 (17 kDa) by CPT both in the presence and in the absence of PD. (B): The expression of LC3-II, a $16 \mathrm{kDa}$ fragment indicating autophagy, did not change during the course of death in either control or experimental situations. (C) expression of $\beta$-tubulin demonstrated equivalent loading of protein samples. In summary, CPT marginally increases the activation of caspase 3 with or without PD but does not affect the appearance of LC3-II. (b) C8 cells treated with CPT or CPT + PD for 8 or 18 hours were fixed for electron microscopy. Untreated control C8 cells (A) and PD treated cells (B) were elongated and displayed large normal nuclei. Cells exposed to CPT in the absence ((C), (E)) or presence ((D), (F)) of PD showed features of apoptosis ((C) and (D)) after 8 hours as well as vacuolization and secondary necrosis after 18 hours $((E)$ and $(\mathrm{F})$ ).

These three dsRNAs (Cdk5-1, Cdk5-2, and Cdk5-3) were used as control (Cdk5-2) and experimental dsRNA in COS7 cells. Percentage of cell death was determined by trypan blue exclusion. As shown in Figure 4(b), in control COS-7 cells, $25 \mu \mathrm{M}$ CPT can induce $61.2 \%$ cell death by 48 hours in nontransfected cells, compared to $56.7 \%, 60.8 \%$, and $61.2 \%$ of cell death in Cdk5-1-, Cdk5-2-, and Cdk5-3-transfected cells, respectively. No significant difference of cell death 


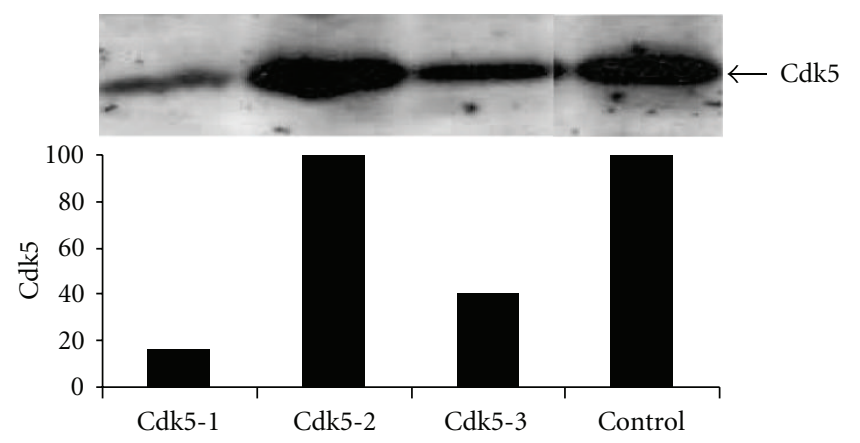

(a)

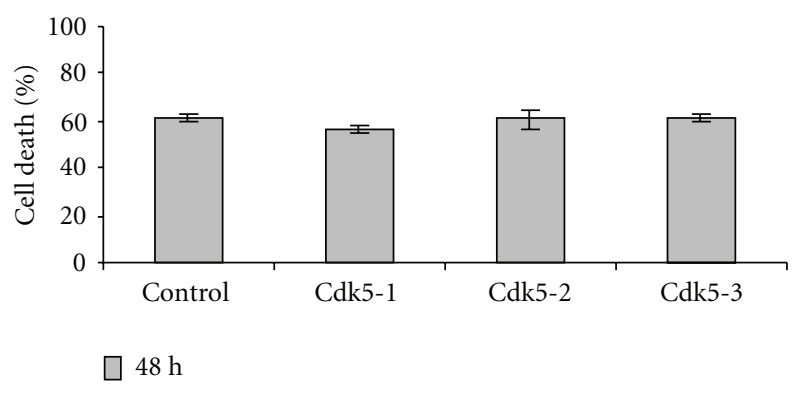

(b)

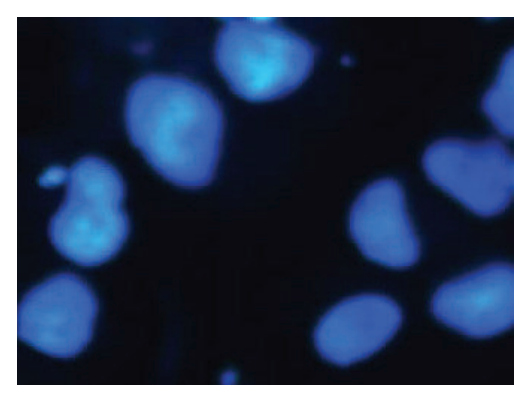

(A)

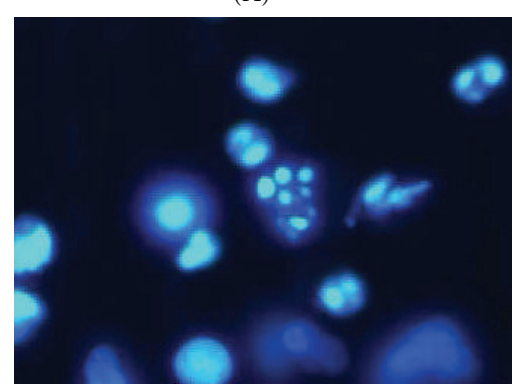

(D)

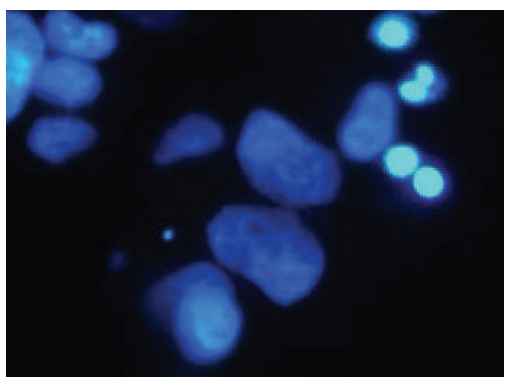

(B)

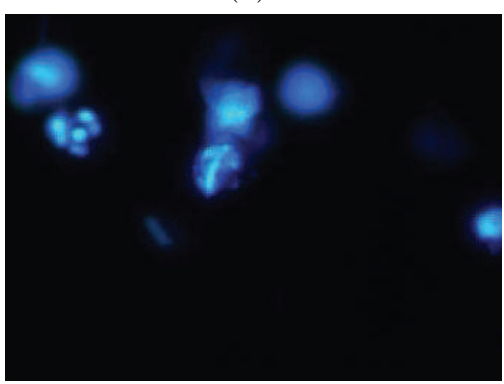

(E)

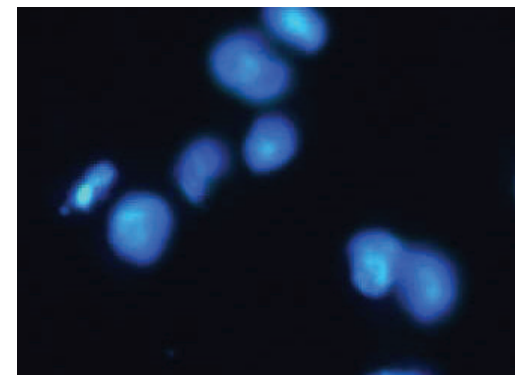

(C)

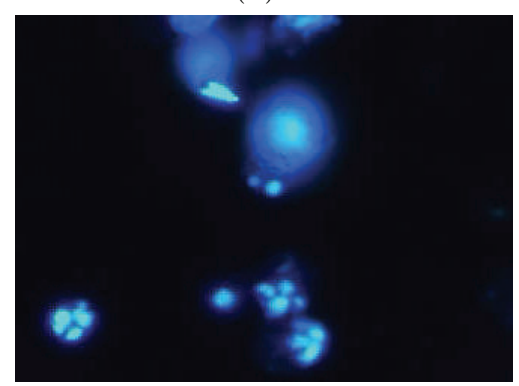

(F)

(c)

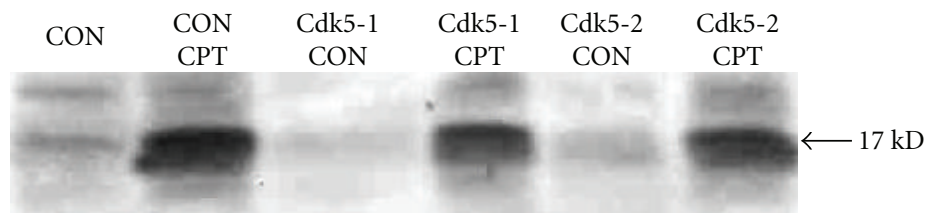

(d)

FIGURE 4: Inhibition of Cdk5 expression does not protect cells from death. (a) COS-7 cells transfected with dsRNA (Cdk5-1, Cdk5-2, Cdk53 ) were collected and lysed by RIPA buffer. Western blot of equal amounts of cell lysates from COS-7 cells showed Cdk5 expression in all cells (A), and the amount of Cdk5 was measured by densitometry (B). dsRNA of Cdk5-1 and Cdk5-3 downregulated Cdk5 expression. (b) COS-7 cells transfected with Cdk5-1, 5-2, or 5-3 dsRNA were treated with $25 \mu \mathrm{M}$ CPT for 48 hours, and cell death was measured by trypan blue exclusion. Downregulation of Cdk5 by RNAi did not affect the amount of cell death. The amount of cell death was calculated by subtracting the amount of cell death in untreated control cells. The error bars represent the standard deviation from at least three individual experiments. (c) COS-7 cells treated with $25 \mu \mathrm{M}$ CPT for 48 hours were fixed with $4 \%$ paraformaldehyde and stained with Hoechst 33258 dye. Apoptotic cells manifest condensed and fragmented nuclei as is seen in (D), (E), and (F). (A) Control cells; (D) CPT-exposed control cells; (B) cells transfected with Cdk5-1; (E) cells transfected with Cdk5-1 and treated with CPT; (C) cells transfected with Cdk5-2; (F) cells transfected with Cdk5-2 and treated with CPT. The numbers and percent of dead cells were not calculated but appeared to be consistent with the results presented in Figure 4(b). (d) COS-7 cells were incubated with $25 \mu \mathrm{M}$ CPT for 48 hours with or without a dsRNA. After 48 hours incubation, cells were collected and proteins were extracted. Western blots of cell lysates from cells showed the activation caspase-3 by CPT both in the control cells and transfected cells. 


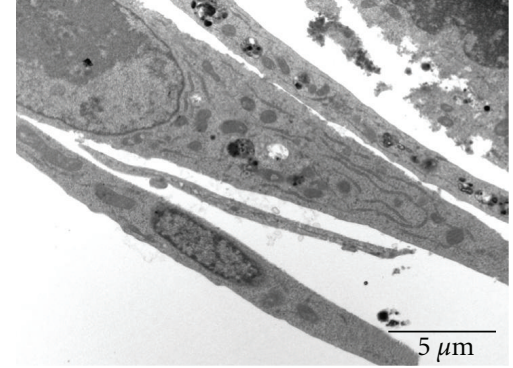

(a)

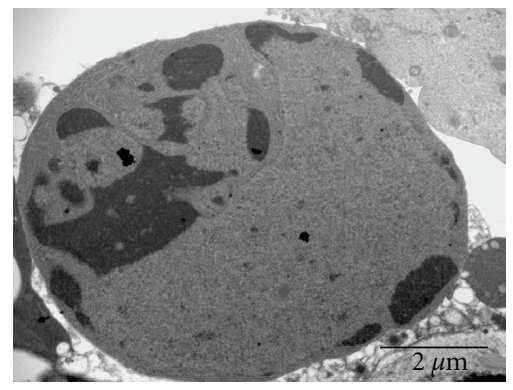

(c)

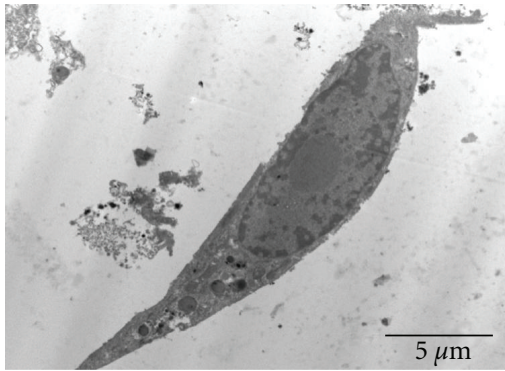

(b)

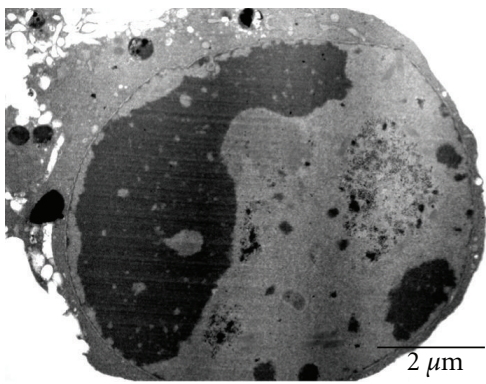

(d)

FIGURE 5: Inhibition of Cdk5 expression does not protect cells from death. COS-7 cells treated with CPT at 48 hours with or without transfection of Cdk5 dsRNA were fixed for electron microscopy. (a) and (b) Untreated cells transfected with Cdk5-1 (a) or Cdk5-2 (b) are elongated and display large nuclei, comparable to controls that were not transfected (see Figure 3(b)(A); otherwise not illustrated). (c) and (d) CPT-exposed dying cells in control (c) and transfected with Cdk5-1 dsRNA (d) were apoptotic. An apoptotic cell has a condensed nucleus and cytoplasm and increased electron density while the chromatin is coalesced and electron-dense. Cells killed by CPT are apoptotic regardless of the concentration of Cdk5.

in transfected cells was seen compared to nontransfected cells exposed to CPT 48 hours. Thus, downregulation of expression of Cdk5 to any level by RNAi did not affect the level of cell death induced by CPT.

\subsection{The Mode of Cell Death Is Not Altered by Downregulation} of Cdk5. It remained possible that Cdk5 would affect the mode of cell death. We exposed cells transfected with Cdk5-1 and Cdk5-2 to $25 \mu \mathrm{M}$ CPT for 48 hours and fixed them for Hoechst staining. As shown in Figure 4(c), nuclear fragmentation was detected in all conditions after induction of cell death, indicating that the downregulation of expression of Cdk5 does not affect apoptosis, as indicated by nuclear fragmentation, during cell death induced by CPT. In a further test, activation of caspase-3 during cell death induced by CPT clearly correlated with the induction of cell death with CPT at 48 hours (Figure 4(d)). Thus, CPT induces caspase- 3 activation during cell death irrespective of downregulation of Cdk5 expression by RNAi.

Finally, we used electron microscopy to evaluate morphological changes during cell death. Apoptotic cells display cell rounding and chromatin condensation as well as chromatin margination. Cdk5-1- and Cdk5-2-transfected but otherwise untreated cells were elongated cells with normal morphology (Figures 5(a) and 5(b)), indicating that transfection of Cdk5 did not by itself affect the morphology of cells. After exposure to CPT for 48 hours, cells that had not been transfected but were exposed to CPT had apoptotic morphology such as condensed and fragmented chromatin and rounding and shrinkage (Figure 5(c)) as did the Cdk51 transfected cells (Figure 5(d)). Thus the downregulation of Cdk5 did not affect the type of cell death. Inhibition of Cdk5 expression did not alter the morphological changes during cell death. The mode of cell death with downregulation of Cdk5 is also apoptotic.

\section{Discussion}

Cdk5 was activated in bim -/- mouse embryos during cell death induced by $\mathrm{CP}$, indicating that the activation of Cdk5 does not require activity of Bim. Our previous data have shown that the activation of Cdk 5 also is independent of the activity of caspase-3 [25]. This independence might suggest that Cdk5 activation is upstream of caspase-3 and Bim activation in the cell death signaling transductions, which is consistent with claims that action of Cdk5 is upstream of caspase-3 activation [19] and Cdk5 is an upstream regulator of mitochondrial dysfunction [34], that Cdk5 is involved in cell death signaling pathways parallel to the caspase cascade, and that Cdk5 is activated because cells die but that Cdk5 plays no functional role in the death. Cdk5 is activated and p25 is generated during cell death in cathepsin B, D, or L null cells, indicating that Cdk5 activation during cell death does not require activation by cathepsin B, D, or L. Inhibition 
of generation of $\mathrm{p} 25$ by calpain likewise confirms that $\mathrm{Cdk} 5$ can be activated without $\mathrm{p} 25$. The consistent level of Cdk5 protein expression in wild type cells and cathepsin $\mathrm{B}$, or $\mathrm{D}$, or $\mathrm{L}-/$ - cells either untreated or treated with CPT, confirms our previous but less documented argument $[20,25]$ that Cdk5 is a relatively stable protein and that Cdk5 activity is regulated not at either transcriptional or translational level, but at a posttranslational level. Since Cdk5 activity is not affected by knockout of lysosomal proteases, activation of Cdk5 during cell death cannot be placed downstream of lysosomal proteases.

Clearly, Cdk5 plays an important role in the differentiation of neurons [4-10,27,28], and perhaps in differentiating muscle. However, in other cells and in mature muscle it seems to be activated during cell death and perhaps only during cell death. The mechanism and biological purpose of its activation is unknown.

The calpain inhibitor PD does not reduce the amount of cell death in either untreated control or CPT-treated cells. Inhibiting generation of p 25 and p29 [25] does not prevent the generation of the hallmarks of CPT-provoked apoptotic cell death, caspase- 3 activation, and nuclear condensation. Thus, even when generation of Cdk5 activator p25 and p29 is blocked, cells die through the same signaling pathways.

Cdk 5 can still be activated when Cdk5/p25 and Cdk5/p29 activity is inhibited, and many proteins have been suggested as potential activators of $\mathrm{Cdk} 5$, but none have been associated with cell death. Recently, RINGO, a Xenopus protein, was shown to activate Cdk5 in Xenopus oocytes [32, 37]. p35, which is involved in cell differentiation, is less stable than p25, a known activator, and is degraded faster than p 25 but Cdk5/p35 activity also correlates with cell death. For example, enhancement of Cdk5 and p35 immunoreactivity is observed in the apoptotic cell body following ischemia [38], and elevated Cdk5 and p35 activity have been detected in dying oocytes [17]. Thus, it is possible that $\mathrm{p} 35$ by itself can activate Cdk5.

Inhibition of Cdk 5 expression or Cdk 5 activation does not affect the amount of cell death induced by CPT. Neurons from Cdk5 knockout mice are known to undergo apoptosis, indicating the existence of Cdk5-independent cell death pathways [39]. The inactivation of Cdk5 in cells exposed to CPT and PD for 18 hours may reflect the shorter half-life of p35 or, alternatively, inactivation or loss of the enzyme from these necrotic cells. Our results are consistent with the interpretation that the presence of activated Cdk5 does not affect the number of spontaneous or induced deaths.

Although Cdk5 is routinely activated during cell death, cells can die without Cdk5 activity and the type of cell death is not altered by inhibition of Cdk5 activity. Thus Cdk5 activation appears to result from changes during cell death rather than causing or otherwise influencing cell death. Nevertheless, the consistent activation of Cdk5 during many or most types of cell death [40] indicates that the metabolic changes that activate Cdk5 must be of substantial interest, potentially revealing mechanisms or vulnerabilities common to most forms of cell death. We must still determine what these changes are.

\section{Acknowledgments}

This work was supported by funding from NIH and PSC CUNY Grants to Dr. Zahra Zakeri. The authors also thank Drs. Marianne Boes and Scott Lowe for providing them with the cells and Drs. Yong Zhu and Lin Lin for technical advice.

\section{References}

[1] L.-H. Tsai, T. Takahashi, V. S. Caviness Jr., and E. Harlow, "Activity and expression pattern of cyclin-dependent kinase 5 in the embryonic mouse nervous system," Development, vol. 119, no. 4, pp. 1029-1040, 1993.

[2] J. Lew, R. J. Winkfein, H. K. Paudel, and J. H. Wang, "Brain proline-directed protein kinase is a neurofilament kinase which displays high sequence homology to p34cdc2," The Journal of Biological Chemistry, vol. 267, no. 36, pp. 2592225926, 1992.

[3] F. A. Dhariwala and M. S. Rajadhyaksha, "An unusual member of the Cdk family: Cdk5," Cellular and Molecular Neurobiology, vol. 28, no. 3, pp. 351-369, 2008.

[4] Y. Hirota, T. Ohshima, N. Kaneko, et al., "Cyclin-dependent kinase 5 is required for control of neuroblast migration in the postnatal subventricular zone," Journal of Neuroscience, vol. 27, no. 47, pp. 12829-12838, 2007.

[5] L. Connell-Crowley, M. Le Gall, D. J. Vo, and E. Giniger, "The cyclin-dependent kinase Cdk5 controls multiple aspects of axon patterning in vivo," Current Biology, vol. 10, no. 10, pp. 599-602, 2000.

[6] S. Rakić, C. Davis, Z. Molnár, M. Nikolić, and J. G. Parnavelas, "Role of p35/Cdk5 in preplate splitting in the developing cerebral cortex," Cerebral Cortex, vol. 16, supplement 1, pp. i35-i45, 2006.

[7] J. L. Rosales, J. D. Ernst, J. Hallows, and K.-Y. Lee, "GTPdependent secretion from neutrophils is regulated by Cdk5," The Journal of Biological Chemistry, vol. 279, no. 52, pp. 53932-53936, 2004.

[8] R. Homayouni and T. Curran, "Cortical development: Cdk5 gets into sticky situations," Current Biology, vol. 10, no. 9, pp. R331-R334, 2000.

[9] Y. Miyamoto, J. Yamauchi, J. R. Chan, et al., "Cdk5 regulates differentiation of oligodendrocyte precursor cells through the direct phosphorylation of paxillin," Journal of Cell Science, vol. 120, no. 24, pp. 4355-4366, 2007.

[10] A. H. Hawasli and J. A. Bibb, "Alternative roles for Cdk5 in learning and synaptic plasticity," Biotechnology Journal, vol. 2, no. 8, pp. 941-948, 2007.

[11] X. Xin, F. Ferraro, N. Bäck, B. A. Eipper, and R. E. Mains, "Cdk5 and Trio modulate endocrine cell exocytosis," Journal of Cell Science, vol. 117, no. 20, pp. 4739-4748, 2004.

[12] E.-A. Choe, L. Liao, J.-Y. Zhou, et al., "Neuronal morphogenesis is regulated by the interplay between cyclin-dependent kinase 5 and the ubiquitin ligase mind bomb 1," Journal of Neuroscience, vol. 27, no. 35, pp. 9503-9512, 2007.

[13] Y. Feng and C. A. Walsh, "Protein-protein interactions, cytoskeletal regulation and neuronal migration," Nature Reviews Neuroscience, vol. 2, no. 6, pp. 408-416, 2001.

[14] J. C. Cruz and L.-H. Tsai, "Cdk5 deregulation in the pathogenesis of Alzheimer's disease," Trends in Molecular Medicine, vol. 10, no. 9, pp. 452-458, 2004.

[15] Q. Guo, "When good Cdk5 turns bad," Science of Aging Knowledge Environment, vol. 2006, no. 5, article pe5, 2006.

[16] J. Zhang and G. V. W. Johnson, "Tau protein is hyperphosphorylated in a site-specific manner in apoptotic neuronal PC12 
cells," Journal of Neurochemistry, vol. 75, no. 6, pp. 2346-2357, 2000.

[17] Q. Zhang, H. S. Ahuja, Z. Zakeri, and D. J. Wolgemuth, "Cyclin-dependent kinase 5 is associated with apoptotic cell death during development and tissue remodeling," Developmental Biology, vol. 183, no. 2, pp. 222-233, 1997.

[18] Z. H. Cheung, A. K. Y. Fu, and N. Y. Ip, "Synaptic roles of Cdk5: implications in higher cognitive functions and neurodegenerative diseases," Neuron, vol. 50, no. 1, pp. 13-18, 2006.

[19] T. Sandal, C. Stapnes, H. Kleivdal, L. Hedin, and S. O. Døskeland, "A novel, extraneuronal role for cyclin-dependent protein kinase 5 (CDK5): modulation of cAMP-induced apoptosis in rat leukemia cells," The Journal of Biological Chemistry, vol. 277, no. 23, pp. 20783-20793, 2002.

[20] Y. Zhu, L. Lin, S. Kim, D. Quaglino, R. A. Lockshin, and Z. Zakeri, "Cyclin dependent kinase 5 and its interacting proteins in cell death induced in vivo by cyclophosphamide in developing mouse embryos," Cell Death and Differentiation, vol. 9, no. 4, pp. 421-430, 2002.

[21] J. L. Rosales and K.-Y. Lee, "Extraneuronal roles of cyclindependent kinase 5," BioEssays, vol. 28, no. 10, pp. 1023-1034, 2006.

[22] A. K. Upadhyay, A. K. Ajay, S. Singh, and M. K. Bhat, "Cell cycle regulatory protein $5(\mathrm{cdk} 5)$ is a novel downstream target of ERK in carboplatin induced death of breast cancer cells," Current Cancer Drug Targets, vol. 8, no. 8, pp. 741-752, 2008.

[23] H. S. Ahuja, W. James, and Z. Zakeri, "Rescue of the limb deformity in hammertoe mutant mice by retinoic acidinduced cell death," Developmental Dynamics, vol. 208, no. 4, pp. 466-481, 1997.

[24] F. Gao, U. Jütting, K. Rodenacker, P. Gais, and P.-Z. Lin, "Relevance of chromatin features in the progression of esophageal epithelial severe dysplasia," Analytical Cellular Pathology, vol. 13, no. 1, pp. 17-28, 1997.

[25] L. Lin, Y. Ye, and Z. Zakeri, "P53, Apaf-1, caspase-3, and -9 are dispensable for Cdk5 activation during cell death," Cell Death and Differentiation, vol. 13, no. 1, pp. 141-150, 2006.

[26] L. Cagnon and O. Braissant, "Role of caspases, calpain and cdk5 in ammonia-induced cell death in developing brain cells," Neurobiology of Disease, vol. 32, no. 2, pp. 281-292, 2008.

[27] M. Slevin and J. Krupinski, "Cyclin-dependent kinase-5 targeting for ischaemic stroke," Current Opinion in Pharmacology, vol. 9, no. 2, pp. 119-124, 2009.

[28] P. Paoletti, I. Vila, M. Rifé, J. M. Lizcano, J. Alberch, and S. Ginés, "Dopaminergic and glutamatergic signaling crosstalk in Huntington's disease neurodegeneration: the role of p25/cyclin-dependent kinase 5," Journal of Neuroscience, vol. 28, no. 40, pp. 10090-10101, 2008.

[29] L.-H. Teai, I. Delalle, V. S. Cavness Jr., T. Chae, and E. Harlow, "p35 is a neural-specific regulatory subunit of cyclindependent kinase 5," Nature, vol. 371, no. 6496, pp. 419-423, 1994.

[30] D. Tang, J. Yeung, K.-Y. Lee, et al., "An isoform of the neuronal cyclin-dependent kinase 5 (Cdk5) activator," The Journal of Biological Chemistry, vol. 270, no. 45, pp. 26897-26903, 1995.

[31] R. Donnellan and R. Chetty, "Cyclin E in human cancers," The FASEB Journal, vol. 13, no. 8, pp. 773-780, 1999.

[32] A. Dinarina, L. H. Perez, A. Davila, M. Schwab, T. Hunt, and A. R. Nebreda, "Characterization of a new family of cyclindependent kinase activators," Biochemical Journal, vol. 386, no. 2, pp. 349-355, 2005.
[33] D. I. Orellana, R. A. Quintanilla, and R. B. Maccioni, "Neuroprotective effect of TNF $\alpha$ against the $\beta$-amyloid neurotoxicity mediated by CDK5 kinase," Biochimica et Biophysica Acta, vol. 1773, no. 2, pp. 254-263, 2007.

[34] U. K. Laemmli, "Cleavage of structural proteins during the assembly of the head of bacteriophage T4," Nature, vol. 227, no. 5259, pp. 680-685, 1970.

[35] K.-H. Sun, Y. de Pablo, F. Vincent, and K. Shah, "Deregulated Cdk5 promotes oxidative stress and mitochondrial dysfunction," Journal of Neurochemistry, vol. 107, no. 1, pp. 265-278, 2008.

[36] E. J. Morris, E. Keramaris, H. J. Rideout, et al., "Cyclindependent kinases and p53 pathways are activated independently and mediate Bax activation in neurons after DNA damage," Journal of Neuroscience, vol. 21, no. 14, pp. 50175026, 2001.

[37] A. R. Nebreda, "CDK activation by non-cyclin proteins," Current Opinion in Cell Biology, vol. 18, no. 2, pp. 192-198, 2006.

[38] T. Hayashi, M. Sakurai, K. Abe, and Y. Itoyama, "DNA fragmentation precedes aberrant expression of cell cyclerelated protein in rat brain after MCA occlusion," Neurological Research, vol. 21, no. 7, pp. 695-698, 1999.

[39] B.-S. Li, L. Zhang, S. Takahashi, et al., "Cyclin-dependent kinase 5 prevents neuronal apoptosis by negative regulation of c-Jun N-terminal kinase 3," The EMBO Journal, vol. 21, no. 3, pp. 324-333, 2002.

[40] J. H. Weishaupt, L. Kussmaul, P. Grötsch, et al., "Inhibition of CDK5 is protective in necrotic and apoptotic paradigms of neuronal cell death and prevents mitochondrial dysfunction," Molecular and Cellular Neuroscience, vol. 24, no. 2, pp. 489502, 2003. 

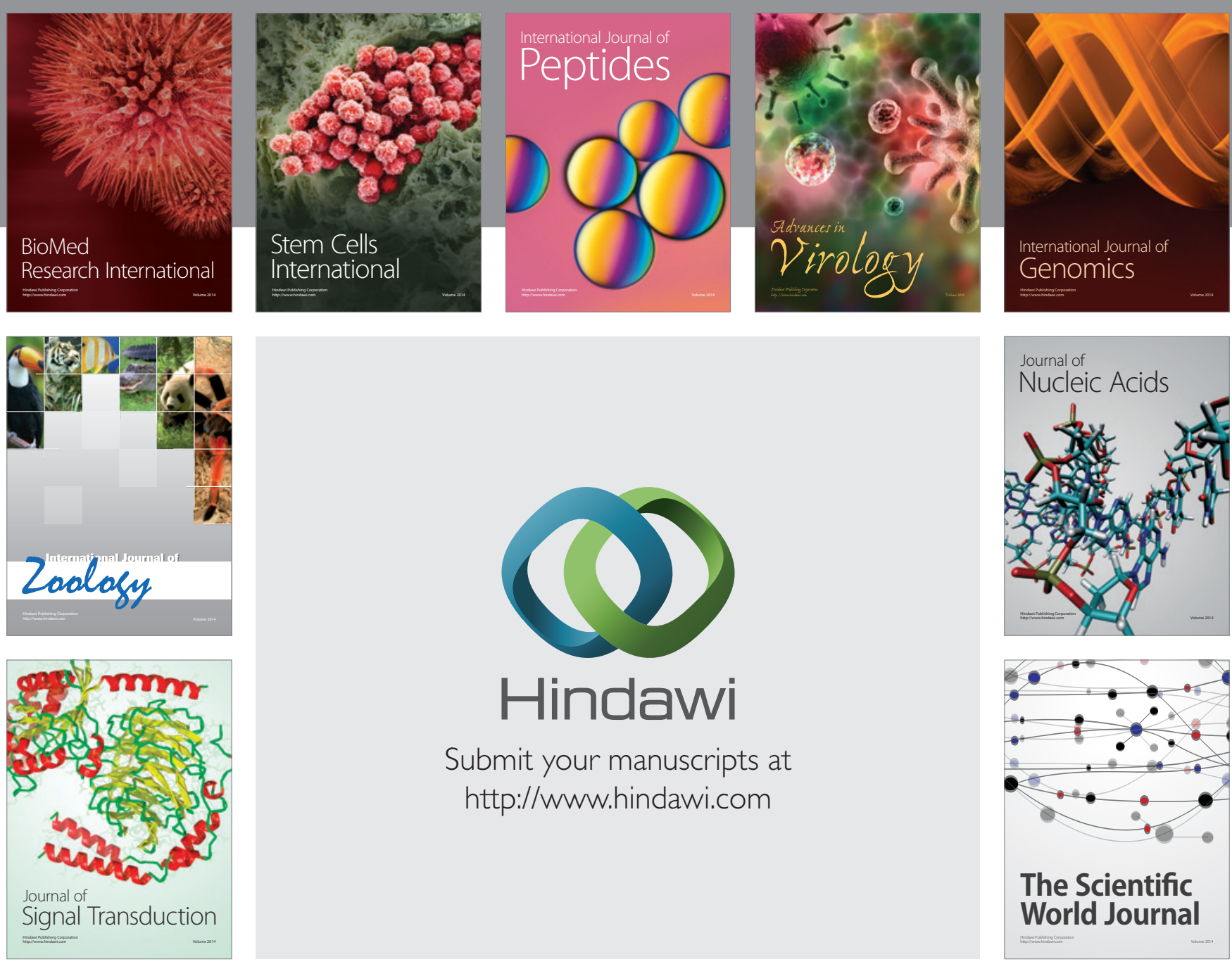

Submit your manuscripts at

http://www.hindawi.com
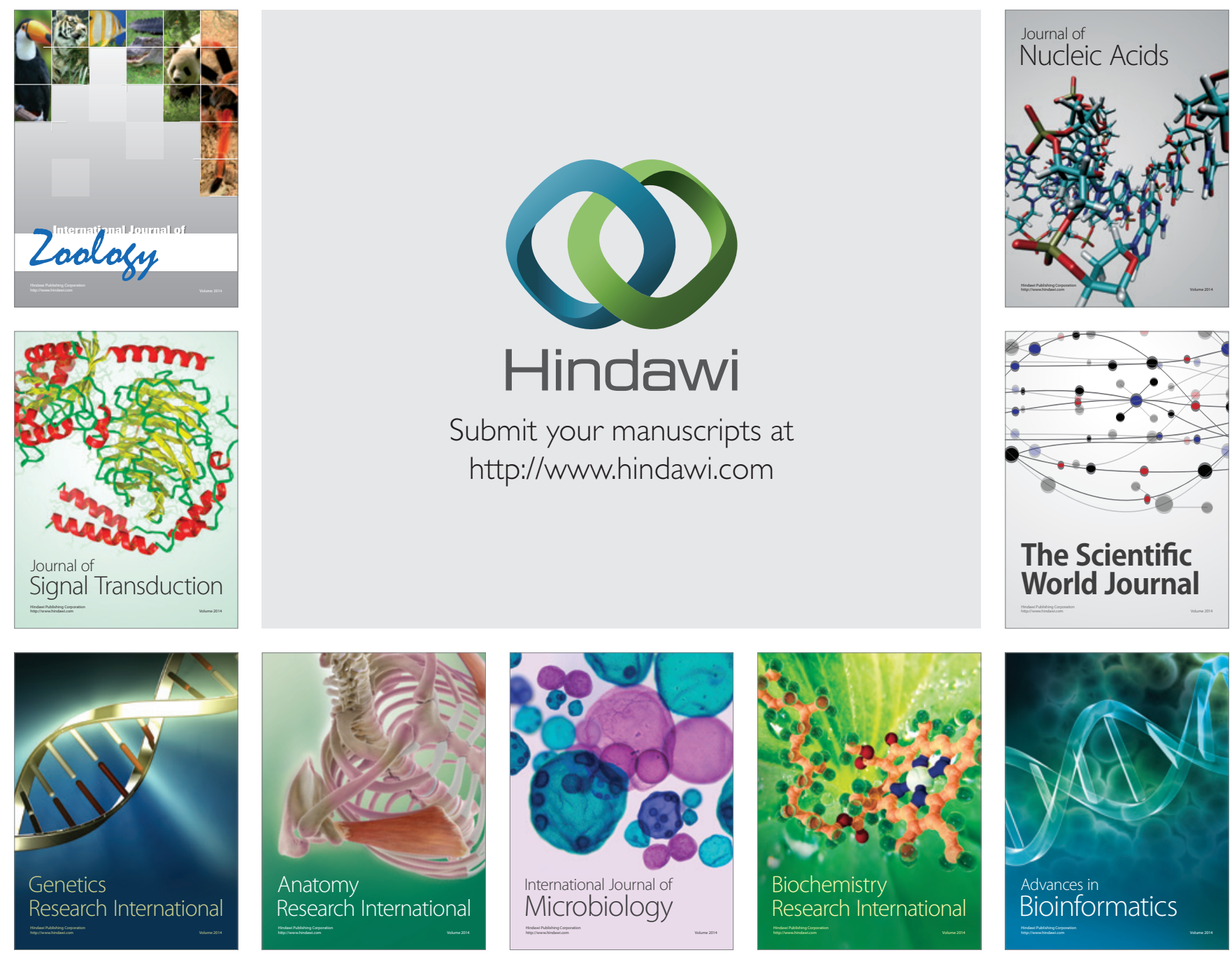

The Scientific World Journal
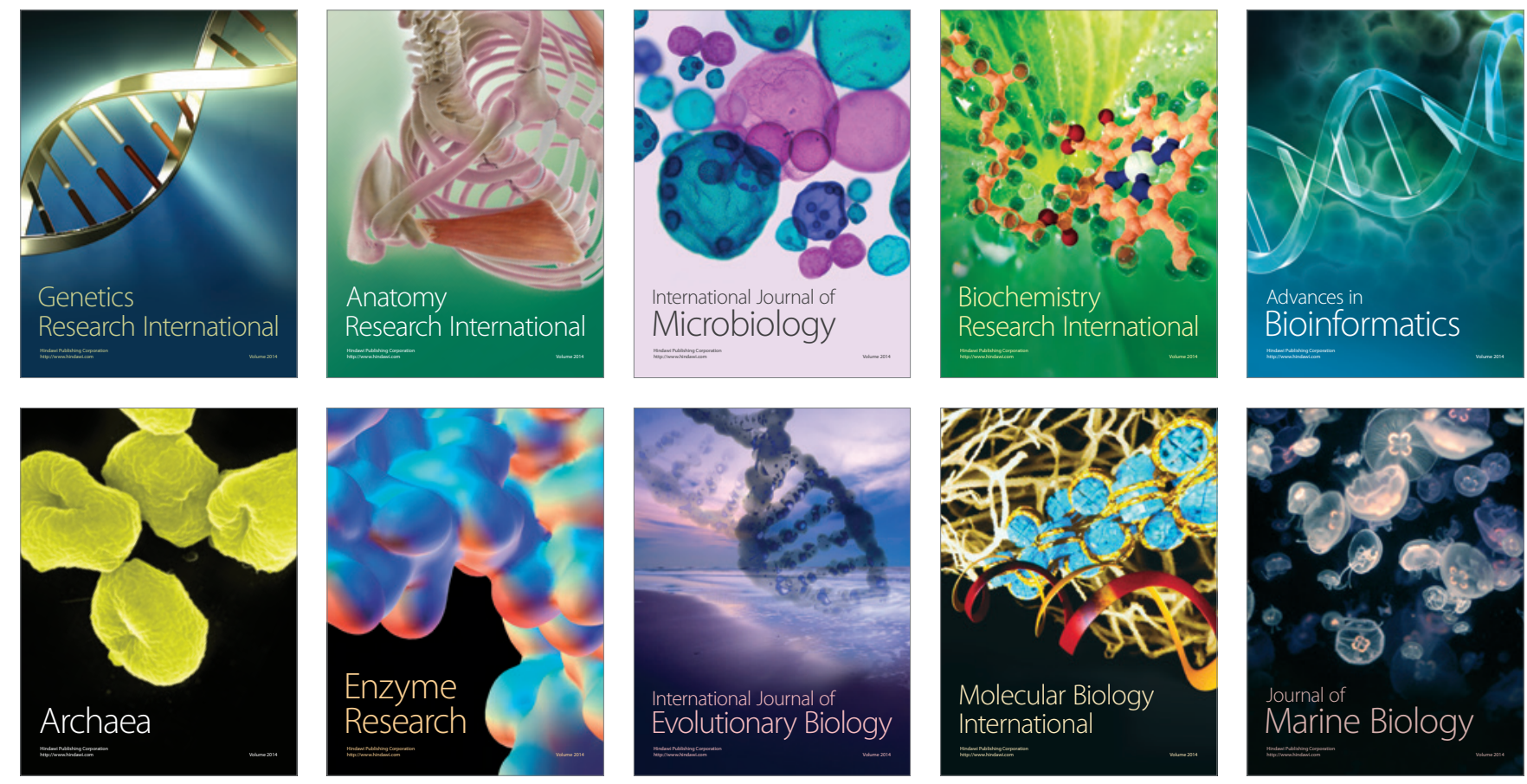